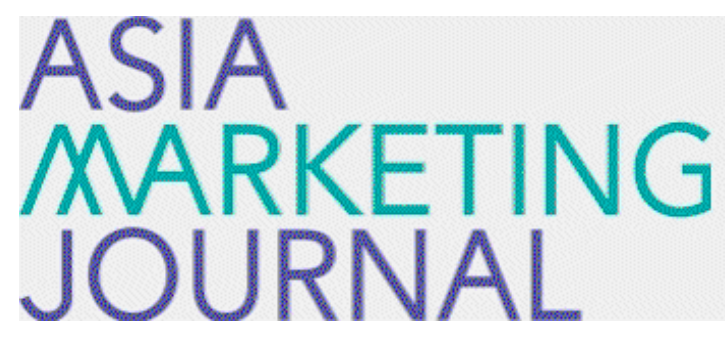

ASIA MARKETING JOURNAL

Volume 20 | Issue 2

Article 2

7-30-2018

\title{
Social Comparison Theory and Interpersonal Contact
}

Y. Jin Youn

Kiwan Park

Follow this and additional works at: https://amj.kma.re.kr/journal

Part of the Marketing Commons

\section{Recommended Citation}

Youn, Y. Jin and Park, Kiwan (2018) "Social Comparison Theory and Interpersonal Contact," Asia Marketing Journal: Vol. 20 : Iss. 2 , Article 2.

Available at: https://doi.org/10.15830/amj.2018.20.2.41

This Article is brought to you for free and open access by Asia Marketing Journal. It has been accepted for inclusion in Asia Marketing Journal by an authorized editor of Asia Marketing Journal. 


\title{
Social Comparison Theory and Interpersonal Contact: The Influence of Incidental Envy on Contacting Higher or Lower Status Others*
}

\author{
Y. Jin Youn** \\ Kiwan Park $^{* * *}$
}

\begin{abstract}
Incidental envy influences behavior in various domains. However, no research, to date, has investigated whether incidental envy influences interpersonal behavior toward others who are unrelated to the emergence of the emotion. That is, the literature is silent on how those who experience incidental envy engage in interpersonal contact and how this may affect consumers. In this paper, we address this question by investigating the influence of incidental envy on interpersonal contact with others of higher or lower status based on the social comparison theory. We demonstrate that incidental envy (versus a neutral emotion) motivates people to contact higher status others to facilitate upward assimilation (experiments 1 and 2). We also show that when competition (a situational factor that heightens the personal relevance of the interaction with the target) is involved, individuals who feel envy (versus a neutral emotion) are more likely to contact lower status others to engage in downward contrast (experiment 3). We conclude with a discussion of the practical implications of our findings.
\end{abstract}

Key words: downward contrast, incidental envy, interpersonal contact, social comparison, upward assimilation

Imagine that a person becomes envious of a friend (e.g., a promotion at work, an extravagant purchase, an engagement), while browsing through social-networking-services (SNS) on the way to work. Although she does not realize it, feelings of envy linger after she arrives at her destination. Will this lingering envy influence her interpersonal behavior in the workplace?

\footnotetext{
* The authors gratefully acknowledge the financial support from the Institute of Management Research, Seoul National University

** SNU Business School, Seoul National University (yj0925@snu.ac.kr), Corresponding Author

*** SNU Business School, Seoul National University (kiwanp@snu.ac.kr)
} 
Furthermore, will incidental envy affect her preference toward certain products that may increase the possibility of contacting higher or lower status others? In this paper, we investigate the influence of incidental envy on interpersonal behavior and discuss practical implications for marketers. Specifically, we test whether incidental envy influences the tendency to contact people of either higher or lower status in subsequent irrelevant interpersonal situations.

As envy typically occurs when individuals realize that they lack what another person has, it tends to make people aware of their own inferiority (Bers and Rodin 1984; Parrott 1991). Thus, individuals who experience envy are motivated to overcome this threat and selfenhance by engaging in various types of behavior (Polman and Ruttan 2012; Van de Ven et al. 2011a; Van de Ven et al. 2011b). Specifically, people often engage in upward or downward social comparison to inflate their egos and restore their sense of self-esteem (Suls and Wheeler 2002). In this paper, we build on prior work on the motivational properties of envy and the social comparison theory by examining how incidental envy influences people's behavior to contact others in subsequent interpersonal contexts.

Based on three experiments, we demonstrate that the way incidental envy leads individuals to contact either higher or lower status others depends on not only the relative status of the target others, but also whether potential competition with others exists. Research on the social comparison theory suggests that people engage in interpersonal contact with upward targets to seek upward assimilation (Taylor and Lobel 1989). However, we demonstrate that although contacting upward targets when facing a threat (here, emanating from feelings of envy) is a more general strategy, the presence of competition with the target may lead people to contact downward targets instead.

When people are in competitive relationships, the personal relevance of the interaction becomes more salient, which is a critical factor known to facilitate downward contrast (Collins 2000). Furthermore, competition presents a win-orlose situation that motivates individuals to engage in interpersonal contact to prove their superiority. In other words, in the presence of competition, contact may be required to prove that they are superior. As such, this paper investigates the role of competition in social comparison by demonstrating how the presence of competition when facing a threat motivates people to contact downward targets.

\section{Motivational Properties of Incidental Envy}

Envy arises when upward social comparison forces individuals to recognize their relative inferiority (Mussweiler et al. 2004; Silver and 
Sabini 1978; Smith et al. 1988). The recognition of one's own disadvantage(s) distinguishes envy from other related negative emotions (e.g., resentment; Smith 1991). Theorists agree that envy evokes two principal affective components that influence behavior: a sense of inferiority and a feeling of ill-will toward envied others (Elster 1989; Parrott and Smith 1993; Salovey 1991; Silver and Sabini 1978; Smith 1991). Various consequences of envy that stem from these affective components have been explored in prior research.

First, feelings of inferiority may make envious individuals more sensitive to what envied others do or have, and motivate them to engage in behaviors that make them feel they are as good as the envied targets. For example, feelings of envy increase one's willingness to pay for the same conspicuous product the envied target owns (Van de Ven et al. 2011a). By doing so, envious people may increase their positive selfevaluation and eventually overcome feelings of inferiority. Second, reducing the relative standing of envied targets or wishing that they fail may enable envious individuals to restore their selfimage and feel the malicious pleasure of schadenfreude (Miceli and Castelfranchi 2007; Parrott and Smith 1993; Van de Ven et al. 2009). Failings on the part of envied others provide people who feel envy with a means to improve their relative standing.

Although feeling envy often leads to utilizing both strategies, recent theorizing suggests that there might be a temporal difference in implementing them. The upward motivation, as compared to the harming intention, is demonstrated to be temporally enduring with a long-term effect (Hoogland et al. 2017; Lange et al. 2018). That is, in subsequent situations after envy is experienced, as in the case of feeling "incidental" envy, the upward motivation to become a better person is likely to remain, while the harming intention rather rapidly subsides. Consistent with this logic, recent studies have shown that the experience of incidental envy motivates people to engage in a wide array of behaviors to increase their positive self-evaluation in irrelevant domains (Belk 2011; Polman and Ruttan 2012; Van de Ven et al. 2011b). For instance, Polman and Ruttan (2012) found that people who experienced incidental envy subsequently perceived themselves as having a higher moral standard than others, with the implication being that after the experience of envy, people are motivated to become "better" (here, more moral) individuals. For the same reason, people who experience incidental envy are more likely to perform better on certain tasks (e.g., anagram task, remote association task; Van de Ven et al. 2011b).

It is worth noting that prior research has mainly focused on how incidental envy motivates people to become "better" by engaging in behaviors to improve their self-image or become a better person. However, in this paper, we test how the tendency to self-enhance following the 
experience of envy is manifested when the opportunity to enhance the self is limited to interpersonal behavior. In such contexts, it may be difficult for individuals to improve their self-image or become a better person because there are no direct personal decisions, tasks, or behaviors to engage in. Instead, self-enhancement is possible rather indirectly through social interaction.

\section{The Influence of Incidental Envy on Social Comparison}

Research on the social comparison theory has demonstrated that social comparison fulfills a self-enhancement function by providing selfknowledge of an individual's relative standing regarding specific attributes (Lockwood and Kunda 1997; Wills 1981; Wood 1989; Wood et al. 1985). This stream of research shows that people engage in social comparison with respect to opinions, beliefs, or abilities when they wish to evaluate or enhance certain facets of their self-image (Festinger 1954; Goethals and Darley 1977). For example, breast cancer patients actively compare themselves to other breast cancer patients to boost their subjective well-being (Wood et al. 1985).

The literature on social comparison shows that both downward and upward comparison may provide the means to self-enhance (Collins
2000; Wood 1989; Wood et al. 1985; Wheeler and Miyake 1992). The downward comparison theory (Will 1981) argues that threatened people are more likely to engage in downward comparison because downward contrast increases their positive self-evaluation. However, this may not always be the case (Wheeler and Miyake 1992). Upward comparison may also lead to positive self-views because people long to have better qualities and believe that they are like betteroff others (i.e., upward assimilation; Collins 2000). Particularly, when there is a possibility of a change in status, upward comparison provides motivation, hope, and inspiration (Lockwood and Kunda 1997; Wood 1989). Thus, the two types of social comparison may have both positive and negative effects on self-enhancement. Downward comparison leads individuals to believe they have relatively superior standing, while at the same time making them realize that their status may decline (Wheeler and Miyake 1992). In contrast, engaging in upward comparison may lead individuals to believe that they are relatively disadvantaged, while also feeling the hope of improvement (Lockwood and Kunda 1997; Wood 1989).

Taylor and Lobel (1989) demonstrated that when people experienced a threat, they could engage in both downward contrast and upward assimilation to enhance their self-image. Research has suggested that downward contrast is more likely to occur in an evaluative context. For example, people are more likely to make explicit 
self-evaluations with others who are in similar (i.e., both have cancer) but worse situations (i.e., the comparison target has worse symptoms; Wood et al. 1985). In other words, downward comparison mostly occurs when people are prompted to evaluate the difference between the target and the self (Taylor et al. 1990; Will 1981).

In contrast to the evaluative comparison made with downward targets, upward assimilation occurs when individuals contact or seek information about upward targets. For example, cancer patients are more likely to interact with fellow patients who are slightly better off physically than with those who are slightly worse off (Molleman et al. 1986). Moreover, cancer patients are more likely to want to know about betteroff others rather than worse-off others (Taylor et al. 1990). Converging evidence suggests that people prefer to contact upward targets rather than downward targets (Taylor and Lobel 1989). The literature suggests that, in general, downward contrast occurs via evaluative comparison while upward assimilation occurs via interpersonal contact. In other words, downward contrast and upward assimilation, as part of social comparison after feeling a threat, can happen simultaneously, but interpersonal contact mostly occurs due to the motivation for upward assimilation.

However, the extant research does not discuss how social comparison works when individuals experience feelings of inferiority emanating from envy. We argue that the lingering feelings of envy motivate people to focus on their relative status among others, and to engage in interpersonal contact with others in terms of status.

\section{The Role of Competition}

Although we hypothesize that people who experience incidental envy (versus a neutral emotion) are more likely to engage in interpersonal contact with higher status others to facilitate upward assimilation, we also hypothesize that in certain circumstances people who feel envy (versus a neutral emotion) may be more likely to contact those with lower status. We predict that people who feel envy (versus a neutral emotion) will be more likely to contact lower status others when they face competition against with the target other.

Competition is a situation in which the goal attainment of the participants is negatively related, such that the victory of one participant comes at the loss of the other (Deutsch 1949). As it is a win-or-lose situation in which the participants may acquire or lose everything, competition stresses the personal relevance of the interaction. Prior research on social comparison stresses that personal relevance makes downward contrast more salient than upward assimilation (Collins 2000). Although downward contrast is likely to arise in an evaluative context rather 
than through interpersonal contact (Taylor et al. 1990; Will 1981), we argue that the nature of competition is critical in motivating people to contact downward others. Competition naturally assumes a situation in which there is interaction between two parties. Therefore, the presence of competition makes interpersonal contact necessary to achieve the purpose of downward contrast. Even in the situations where direct contact seems less critical for competition (e.g., computer games etc.), some type of contact between the two involved parties is necessary (e.g., virtual contact).

Taken together, competition introduces a unique situation in which interpersonal contact is imperative to achieve downward contrast. Thus, we predict that in a competitive situation, where there is a competing goal to achieve, those who experience envy (versus a neutral emotion) are more likely to contact others with lower status to facilitate downward contrast. Although our research is based on the interplay between incidental envy and social comparison theory, we are specifically interested in how incidental envy influences interpersonal contact.

\section{Overview of Studies}

The remainder of this paper is organized as follows. We test the effect of incidental envy on interpersonal contact in three experiments.
We predict that feeling incidental envy (versus a neutral emotion) leads people to contact the target with higher status. In contrast, when competition exists between the individual who feels envy and the target other, individuals who feel envy (versus a neutral emotion) are likely to contact others with lower status. We test our hypotheses on different social targets, namely, an acquaintance at a social gathering (experiment 1), a group of students featured in print advertisements (experiment 2), and a colleague at work (experiment 3 ). In experiments 1 and 2, we demonstrate the validity of contacting a higher status other following the experience of incidental envy (versus a neutral emotion). In experiment 3, we show that individuals who experience envy (versus a neutral emotion) are likely to contact targets with lower status when they are in direct competition with the target person. We conclude with a discussion of the theoretical and practical implications of our findings and provide suggestions for future research.

\section{Experiment 1}

The goal of this experiment was to test how incidental envy affects interpersonal contact in a subsequent irrelevant context. Specifically, we hypothesized that people feeling envy (versus a neutral emotion) would be more likely to want 
to contact others with higher status.

\subsection{Method}

Two hundred and twenty-two individuals $\left(M_{\text {age }}=43.69, S D=15.80\right)$ were recruited from an online panel (Amazon's Mechanical Turk) and randomly assigned to a 2 (emotion: envy versus neutral emotion) $\times 2$ (target status: higher versus lower) $\times 2$ (target gender: male versus female) between-participants design. The gender of the participants was matched with that of the target in the presented vignette, as the literature has showed that superior opposite-sex others tend to evoke mating motives, thereby increasing the likelihood of interpersonal contact (Durante et al. 2011; Hill and Buss 2008a; Hill and Buss 2008b; Hill et al. 2011).

The participants were informed that they would be asked to complete a series of unrelated questionnaires. They first completed an emotioninduction task adapted from prior research (e.g., Fischhoff et al. 2003; Malatesta and Izard 1984), titled "past experience recall." They were then randomly assigned to one of the two emotion-induction conditions. The participants in the envy condition were instructed to visualize and recall a prior experience of envying another person. They were then asked to describe the experience in detail. Those in the neutralemotion condition completed the same task. However, they were asked to visualize, recall, and describe everyday activities that occurred yesterday. This manipulation was based on prior research demonstrating that recalling past episodes in which a certain emotion was experienced could activate both the intended emotion and its motivational properties (Malatesta and Izard 1984; Roseman et al. 1994).

Next, the participants were asked to imagine that they would be attending a party hosted by one of their acquaintances. They were asked to read a vignette about meeting a same-sex fictional target at the party. In the vignette, the participants, while drinking at the bar, met a person, Kate or John, depending on their gender. They were further told that they had never met this person before, but knew some basic information about them. Target status was manipulated in terms of schools attended, outward appearance, and the number of friends at the party. Those in the higher target-status condition were told that this person was from an Ivy League school, had a very successful career, was dressed very well, and seemed to be liked by everyone at the party. In contrast, those in the lower target-status condition were presented with details about a person who was from a local community college and currently unemployed. Furthermore, the participants were told that this person was not dressed very well and did not know many people at the party.

After reading the vignette, the participants reported on their likelihood of hanging out with Kate or John in the future on a 9-point scale $(1=$ not at all, $9=$ very much $)$. Finally, the 
participants rated the fictional person on several dimensions (i.e., "How do you feel toward the person you met at the party?") on 9-point scales in comparison with themselves $(1=$ not smarter, 9 = smarter; 1 = less access to resources, 9 = more access to resources; $1=$ lower status, 9 = higher status; $\alpha=.77$ ). This composite index served as our manipulation check for the perceived status of the target.

\subsection{Results}

First, a 2 (emotion) $\times 2$ (target status $) \times 2$ (target gender) analysis of variance was conducted on the manipulation check for target status. The results revealed a significant main effect of target status, indicating that the participants believed that the target in the higher targetstatus condition was higher in status $(M=$ $6.09, S D=1.51$ ) than the target in the lower target-status condition $(M=4.35, S D=.93$; $F(1,214)=71.50, p<.001)$. No other effects were significant ( $p$ s $>.450)$.

To test the main hypothesis, the same 2 $($ emotion $) \times 2$ (target status) $\times 2$ (target gender) analysis of variance was conducted on the primary dependent measure. The three-way interaction was not significant, nor was any of the effects involving target gender ( $p$ s >.060). The analysis revealed a significant two-way interaction between emotion and target status $(F(1,214)=7.24, p=.008$; Fig. 1). Planned contrasts indicated that the participants were (marginally) less likely to want to hang out with the lower status target when they experienced feelings of envy $(M=5.01, S D=1.91)$ versus neutral emotion $(M=5.94, S D=2.15 ; F(1,214)$ $=3.71, p=.055)$. Importantly, however, when the target status was high, the experience of envy $(M=5.84, S D=2.29)$ led to a higher

〈Figure 1〉 Likelihood of wanting to hang out with the target in the future (experiment 1).

The error bars are based on the 95\% confidence intervals.

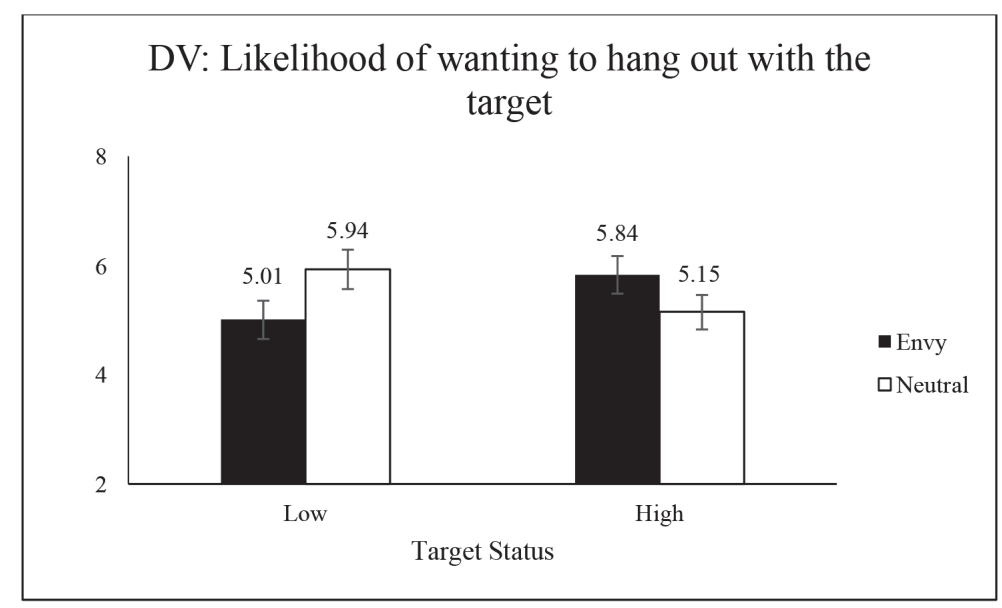

48 ASIA MARKETING JOURNAL Vol. 20 No. 02 July 2018 
likelihood of wanting to hang out with the target in the future than a neutral emotion, albeit with marginal significance ( $M=5.15$, $S D=1.98 ; F(1,214)=3.53, p=.062)$.

\subsection{Discussion}

Experiment 1 provided initial evidence on the effect of incidental envy on interpersonal contact. The results demonstrated that when the target status is high, individuals who felt envy were more likely to contact them as compared to when feeling a neutral emotion. Nevertheless, there were some limitations. Despite the intended results of the manipulation check, the participants might have had different subjective perceptions of their own status, which could have influenced their interpretation of the target-status manipulation. This was particularly likely, given the heterogeneity of the participants recruited from a large online panel. Second, although target gender was matched with that of the participants to rule out a mating-motive explanation (Hill and Buss 2008; Tesser et al. 1988), the manipulation did not rule out all possible motivations that might have been present due to gender incongruence. For example, some people may have romantic motivations toward same-sex others, rather than the opposite sex. In this case, the high-status target manipulation would have directed the participants toward an attractive same-sex target who had strong romantic appeal. Third, as the party scenario depicted a real-life social situation that most of the participants were likely to have experienced, the results might have been based predominantly on their prior experience rather than incidental envy. The participants might have felt pressure to befriend others with higher status at a party due to the prevalent norms at social gatherings. It is also possible that some of the participants aimed to network with a higher (versus lower) status other when attending a social gathering regardless of the potential social comparison they may experience. These limitations were addressed in experiment 2.

\section{Experiment 2}

Experiment 2 had three aims. First, we modified the nature of target status and focused on the single dimension of academic status. To do so, we conducted this experiment on a student pool from a university and manipulated target status based on a widely accepted university ranking (National University Rankings 2016). Second, we asked the participants to state their likelihood of socializing with a group of people, rather than an individual target person. This was likely to mitigate the potential problem of gender incongruence and reduce the influence of personal motivation toward specific target others. Finally, we presented the targets in print advertisements where no 
social situation was given, thereby eliminating the potential influences of other social cues that could affect the predicted results.

\subsection{Method}

Eighty-five individuals $\left(M_{\text {age }}=20.78, S D=\right.$ 5.06) were recruited from a large Midwestern U.S. university and participated in exchange for taking part in a lucky draw for a $\$ 50$ gift card. Experiment 2 used a 2 (emotion: envy versus neutral emotion) $\times 2$ (target status: high versus low) between-participants design. The participants were informed that they would be asked to complete a series of unrelated questionnaires. They first completed an emotioninduction task identical to the one used in experiment 1 .

Next, the participants were asked to evaluate a print advertisement that was ostensibly created by another university (see Appendix). The advertisement portrayed a group of students on graduation day and had a tagline on the bottom that stated, "Cooperation: Take your team to the next level." This tagline was used to reinforce the idea that the students in the print advertisement were on the same team and thus had similar status. The image and tagline used in the advertisement were identical for both the higher and lower target-status conditions. However, those in the higher target-status condition viewed an advertisement with the Harvard University logo at the top, while those in the lower target-status condition viewed an advertisement with the Illinois Valley Community College logo at the top. The participants in this experiment were recruited from a large Midwestern university known to academically rank below Harvard University but above any community college, according to the "National University Rankings, 2016." Additionally, there was a substantial gap between the ranking of the two schools to safely conclude that there is no rivalry between the two universities.

The participants were then asked to answer several questions about the evaluation of the print advertisement (i.e., "How do you feel about the advertisement?", "How much do you like the advertisement?", and "How persuasive is the message of the advertisement below?"). Another question asked how much the participants wanted to hang out with the students in the advertisements $(1=$ not at all, $9=$ very much), which served as our main dependent variable. As in experiment 1, the participants rated the students in the print advertisement on several dimensions on the same 9-point scales. A composite index based on these questions was created ( $\alpha=.84$ ), which served as the manipulation check for the perceived status of the target.

\subsection{Results and Discussion}

To confirm that the students in the two 
advertisements differed in terms of perceived status, a 2 (emotion) $\times 2$ (target status) analysis of variance was conducted on the manipulation check for target status. The results revealed a main effect of target status only, indicating that the participants felt that the Harvard students possessed a higher status ( $M=5.73$, $S D=1.30)$ than the community college students in the advertisements $(M=3.73, S D=1.07$; $F(1,81)=54.52, p<.001)$. No other effects were significant ( $p$ s $>$.690).

A 2 (emotion) $\times 2$ (target status) analysis of variance on the main dependent measure revealed a significant main effect of target status $\left(M_{\text {high }}=4.81, S D_{\text {high }}=2.03\right.$ versus $M_{\text {low }}=3.69, S D_{\text {low }}=1.65 ; F(1,81)=9.61$, $p=.003)$. However, this effect was qualified by a significant two-way interaction between emotion and target status $(F(1,81)=10.56$, $p=.002$; Fig. 2). No other effects were significant ( $p s>.810)$. The planned contrasts indicated that the participants were less likely to want to hang out with the community college students when they experienced envy $(M=2.93, S D=1.62)$ as compared with the neutral emotion $(M=4.11, S D=1.53$; $F(1,81)=4.33, p=.041)$. Importantly, feeling envy led to a higher likelihood of wanting to hang out with the Harvard students ( $M=$ 5.42, $S D=2.06)$ as compared with a neutral emotion $(M=4.05, S D=1.75 ; F(1,81)=$ 6.38, $p=.013)$.

The results of experiment 2 provided stronger evidence for the proposed effect. As mentioned previously, participants who felt envy (versus a neutral emotion) were more likely to want to socialize with the higher status targets than the lower status targets depicted in the print advertisements. These results further strengthen the findings of experiment 1 . As the target

〈Figure 2〉 Likelihood of wanting to hang out with the target in the future (experiment 2).

The error bars are based on the 95\% confidence intervals.

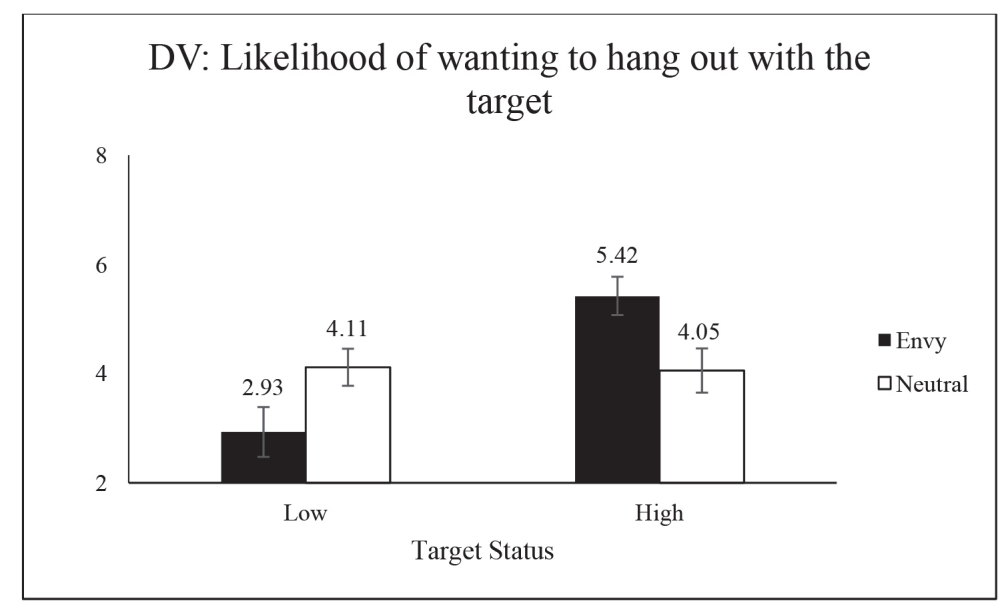


others were depicted in print advertisements, there was no room for the participants' preexisting experience of networking with others at a party to exert any influence. For the same reason, any romantic motivations and social pressure to befriend those with high status were ruled out. The results also enhanced the external validity of our findings in that target status was manipulated based on the participants' actual perception of the two real-life target groups, Harvard versus Illinois Valley Community College students. Taken together, the findings of experiments 1 and 2 demonstrate that those who experience envy are more likely to contact higher status others as compared to those who feel a neutral emotion.

\section{Experiment 3}

Experiment 3 had three objectives. First, we investigated a critical factor that could motivate people who feel envy to contact downward targets due to their heightened need for downward contrast by considering a situation in which the participants faced competition with the target. We hypothesized that in the presence of competition, those who feel envy (versus a neutral emotion) would be more likely to want to contact lower status others. In doing so, we introduced a situation where there was ongoing competition against the fictional target.
Second, we provided convergent validity by using a different interpersonal situation (i.e., the workplace) to test our hypothesis. Finally, to test for a mediated moderation effect, we measured the personal relevance of the interaction with the target in relation to self-enhancement as a possible mediator.

\subsection{Method}

One hundred and ninety-nine individuals were recruited from an online panel (Amazon's Mechanical Turk) and randomly assigned to a 2 (emotion: envy versus neutral emotion) $\times 2$ (target status: high versus low) betweenparticipants design. One hundred and eightyeight participants $\left(M_{\text {age }}=37, S D=12.62\right)$ were included in the analyses, after removing those who stated that they had participated in a similar survey before. To the best of our knowledge, similar recall tasks to induce envy were administered repeatedly for the MTurk participants during the survey period. The participants were informed that they would be completing a series of unrelated questionnaires and were first presented with the emotion induction task, which was identical to that used in the previous two experiments.

Next, the participants were presented with an ostensibly unrelated task containing a detailed scenario about a situation at work. In the scenario, they mentally simulated working as a manager at a large national marketing and 
public relations firm. They were told that they would be participating in a perspective-taking exercise. This cover story was used because most of the participants on the online panel might not have had direct experience with being a manager at a large firm. The participants were then asked to take the role of another individual and put themselves in this person's shoes. The scenario introduced a fictional colleague named M. Forer. No information was provided regarding gender.

The participants in the higher target-status condition received information about M. Forer that was intended to make them believe that M. Forer had a higher status within the organization. Here, we described M. Forer as being promoted to manager slightly before the participants, having graduated from an Ivy league school, being well connected with the right people, and being successful in most of his projects and thus as holding a good reputation among his or her co-workers. In contrast, those in the lower target-status condition received information that M. Forer had a lower status within the organization. They were told that M. Forer had been promoted to manager slightly later than the participants, graduated from a community college, did not hold a good reputation among his or her co-workers, was not well connected with the right people, and was not successful in most of his or her projects. After reading the description of $\mathrm{M}$. Forer, the participants were told that they had been competing with
M. Forer over clients during the past few weeks. They were further told that senior management intended to carry on this policy in the future. Then, the participants were asked about how much they wanted to work with M. Forer in the future on a 9-point scale $(1=$ not at all, 9 = very much). This served as our main dependent variable. As working as a manager at a marketing and public relations firm might not have been an ordinary experience for our participants, the degree to which they took the perspective of the main character was assessed on a 9-point scale ("Thinking back to the perspective-taking exercise, to what degree were able to get into the shoes of the main character?"; 1 = not at all, 9 = very much). This served as our control variable. Then, the participants answered a series of questions regarding M. Forer, which were identical to those in experiments 1 and 2; this served as our manipulation check ( $\alpha=.85$ ). Finally, the participants indicated the degree of personal relevance of interacting with the target ("Do you think spending time with M. Forer may help your career?" and "Do you think spending time with M. Forer may hurt your career?"; $1=$ not at all, $9=$ very much). By reversecoding the second item, we created a composite index for personal relevance of interacting with the target, which we used as our mediator $(\alpha=.66)$. 


\subsection{Results and Discussion}

First, a 2 (emotion) $\times 2$ (target status) analysis of covariance was conducted on the manipulation check, with perspective taking used as a control variable. The results revealed a main effect of target status, indicating that the participants in the higher target-status condition $(M=6.23, S D=1.56)$ perceived M. Forer as having a higher status than those in the lower target-status conditions $(M=$ 3.86, $S D=1.70 ; F(1,184)=99.41, p<.001)$. No other effects were significant ( $p$ s $>$.090). The main effect of target manipulation remained significant with all participants included $(F(1$, 194) $=104.86, p<.001)$ and without controlling for perspective taking $(F(1,184)=99.41, p<$ .001).

The same 2 (emotion) $\times 2$ (target status) analysis of covariance on the main dependent measure revealed a significant main effect of target status $\left(M_{\text {high }}=6.22, S D_{\text {high }}=2.33\right.$ versus $M_{\text {low }}=4.39, S D_{\text {low }}=2.32 ; F(1,183)$ $=27.84, p=.000)$. This was qualified by a significant interaction between emotion and target status $(F(1,183)=7.48, p=.007$; Fig. 3). No other effects were significant ( $p s$ $>$.110). The interaction remained significant even after including those who had previously participated in a similar survey $(F(1,194)=$ 6.33, $p=.013)$ and without controlling for perspective taking $(F(1,184)=6.87, p=$ .009). The planned contrasts indicated that among those in the higher target-status condition, feeling envy $(M=5.75, S D=2.19)$ led to a marginally lower likelihood of wanting to work with the target in the future than a neutral emotion $(M=6.63, S D=2.39 ; F(1,183)=$ 3.39, $p=.067)$. Importantly, however, the pattern was reversed when the target status

〈Figure 3〉 Likelihood of wanting to work with the target in the future (experiment 3). The error bars are based on the 95\% confidence intervals.

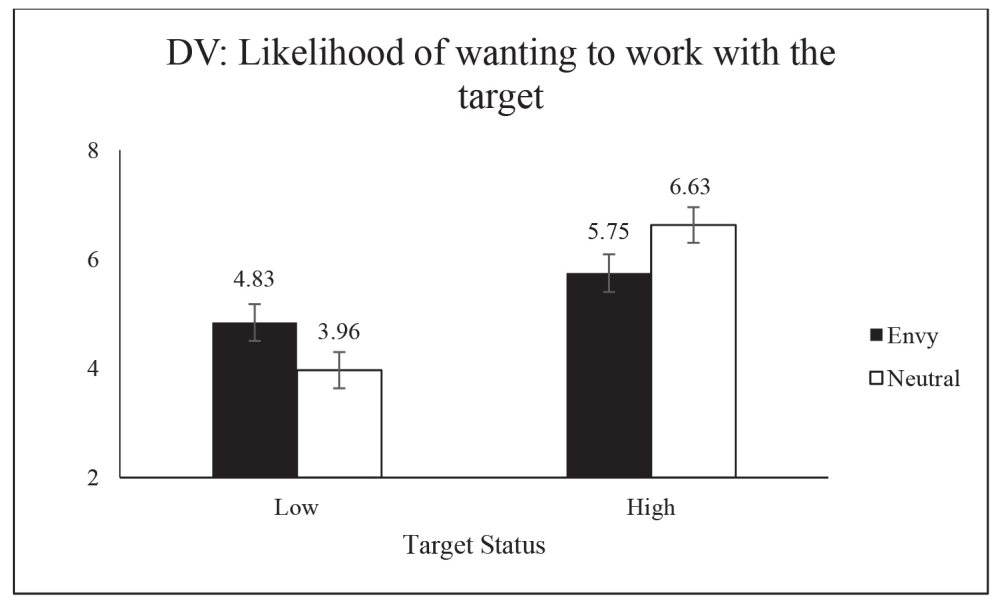


was lower. Specifically, the participants were more likely to want to work with the target in the future when they experienced envy $(M=$ 4.83, $S D=2.22$ ) rather than the neutral emotion $(M=3.96, S D=2.35 ; F(1,183)=$ 4.10, $p=.044)$.

Finally, a mediated moderation analysis was conducted on the composite mediational measure using the PROCESS macro provided by Preacher and Hayes (2004). We predicted that target status would moderate the effect of emotion on the likelihood of wanting to work with the target when controlling for perspective taking, and that this moderation would be mediated by the personal relevance of interacting with the target (Model 8). The predicted indirect effect was significant as the 95\% confidence interval (CI) around the estimate did not include zero $(B=-.76, S E=.24,95 \%$ bootstrap CI $=[-1.25,-.31])$. Specifically, the results demonstrate that when people feel envy (versus a neutral emotion) a lower status target increases the personal relevance of the interaction with the target in relation to self-enhancement which, in turn, positively influences the likelihood of wanting to work with the target in the future $(B=.35, S E=.17,95 \%$ bootstrap CI $=[.02$, .72]). This supports our hypothesis that, in the presence of competition with the target, the increased willingness to engage in interpersonal contact with a lower status target when feeling envy (versus a neutral emotion) is due to the heightened personal relevance of the interaction.

The results of experiment 3 corroborated the role of competition in determining when individuals who experience envy (versus a neutral emotion) chose to contact lower status targets. It was confirmed that in the presence of competition, the participants who experienced envy (versus a neutral emotion) were more likely to engage in interpersonal contact with lower status targets, rather than contacting upward targets. Through the mediated moderation analysis, our findings revealed that the participants who were in the envy (versus a neutral emotion) condition were more likely to contact lower status others due

〈Figure 4〉 Conceptual framework for mediated moderation.

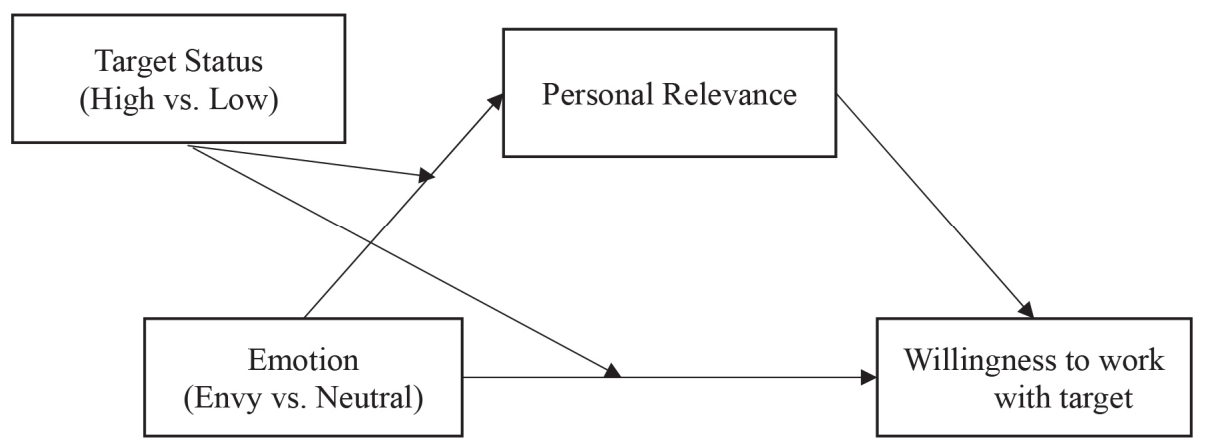


to the heightened personal relevance of interacting with the target other. In other words, the results suggest that when people believe that their gain or loss depends on their counterpart and interpersonal interaction is necessary to achieve gain, they attempt to contact downward targets to facilitate downward contrast.

\section{General Discussion}

The results of our three experimental studies confirm that incidental envy influences people's motivation to engage in interpersonal contact in subsequent interpersonal contexts. Experiments 1 and 2 demonstrated that individuals who experienced incidental envy (versus a neutral emotion) were more likely to contact higher status others. Experiment 3 corroborated that a moderator influenced the observed effect. Specifically, when engaged in competition with the target, those who experienced envy (versus a neutral emotion) were more likely to contact those with lower status.

\subsection{Theoretical Contributions}

We believe that this paper provides important contributions to the literature on envy and the social comparison theory. First, our findings add to the scant literature on incidental envy. The literature on envy has mostly focused on how envious people behave toward the envied other (Hill et al. 2011; Parrott and Smith 1993; Van de Ven et al. 2011a). Little research has investigated how people behave in unrelated contexts after feeling envy. By exploring the role of envy in interpersonal contexts, this paper adds to the existing findings that incidental envy leads to behaviors to increase positive self-evaluation (Polman and Ruttan 2012; Van de Ven et al. 2011b).

Second, the research on incidental envy has failed to provide experimental data on how people behave in interpersonal contexts in relation to the motivational properties of envy. No study, to date, has investigated the relationship between incidental envy and social comparison. Our findings demonstrate the role of incidental envy as a causal agent in affecting interpersonal contact with downward or upward targets.

Third, we add to the literature on the social comparison theory by introducing incidental envy as a self-threat that generates feelings of inferiority. Research on the social comparison theory has investigated people's experiences of various threats, but mainly focuses on those who face physical illness (e.g., breast cancer; Buunk et al. 1990; Taylor and Lobel 1985; Wood et al. 1985). This body of literature demonstrates that people under a certain threat (e.g., breast cancer patients) engage in upward or downward social comparison only in relation to the specific domain in which they are threatened (e.g., other breast cancer patients). 
However, this paper extends this stream of research by testing a specific emotion (here, envy) that induces general feelings of inferiority. Thus, our findings suggest that people with a sense of inferiority are likely to engage in interpersonal contact with those who have higher or lower status depending on the absence or presence of competition.

Finally, we suggest that downward interpersonal contact may be preferred when competition is present. The research on social comparison has demonstrated that threatened people are more likely to engage in downward contrast via explicit self-evaluation in evaluative contexts (Taylor and Lobel 1989). In other words, people explicitly compare themselves with downward targets but avoid interacting with them. In contrast, upward assimilation generally occurs through interpersonal contact and interaction. However, our findings demonstrate that envious people who face competition are likely to attempt to contact lower status targets due to the characteristics of competition. When personal relevance of the interaction is heightened for self-enhancement purposes and interpersonal contact is imperative for downward contrast, those who experience envy (versus a neutral emotion) tend to engage in downward interpersonal contact. This suggests that in certain circumstances downward social comparison can also happen through interpersonal contact or interaction.

\subsection{Practical Implications}

We live in an era when consumers can easily view and access the life of other consumers (e.g., SNS, reality television etc.). This accessibility allows people to actively compare themselves to others. Subsequently, envy is one of the most prevalent emotions that modern consumers experience daily (Belk 2011). Since envy is one of the strongest emotions that motivate consumer behavior, understanding the downstream consequences of incidental envy is not only beneficial for building theory but also for practitioners in marketing. We believe that knowing whether people will contact either higher or lower status others after experiencing envy has broad practical implications for marketers.

First, as the popularity of advertisements on social media has grown, feeling incidental envy from social comparison is becoming more common at the point of viewing promotional messages. Our results suggest that when people feel incidental envy they are more likely to want to contact others with higher status (experiments 1 and 2). Therefore, promoting exclusive memberships or events to meet higher status others may largely benefit from online or mobile advertisements on SNS. Advertising products that can be framed as a gateway to contact higher status others, such as luxury goods, restaurants, or exotic vacation destinations, can be effective to consumers who are coping with feelings of envy.

Second, organizations provide an interpersonal 
context where marketing managers can take advantage of incidental envy strategically. Our findings demonstrate that when there is competition, those who experience envy (versus a neutral emotion) are more likely to want to work with lower status others (experiment 3). This may create a win-win situation for both parties involved (i.e., the person who feels envy and the lower status target). For the person who feels envy, working with a lower status other will give them the opportunity to overcome the feelings of inferiority by engaging in downward contrast. On the other hand, the lower status target, who is not under the influence of incidental envy, may benefit from this interaction as interpersonal contact with higher status others provide motivation, hope, and inspiration (Lockwood and Kunda 1997; Wood 1989). Marketing managers can utilize this finding to stimulate sales representatives to boost sales. If certain sales representatives feel incidental envy, either toward their customers or superiors within the organization, they will be more likely to team up with lower status staff as an attempt to overcome envy. Here, high status sales representatives will overcome feelings of envy and will be able to regain confidence. In contrast, the lower status staff will have an opportunity to work with higher status (i.e., better performance with higher skills) employees and learn how to excel and increase sales.

\subsection{Limitations and Future Research Directions}

Despite our meaningful contributions, this paper has several limitations. First, we do not explore the influence of the two types of envy (i.e. malicious versus benign envy; Van de Ven et al. 2009; Van de Ven et al. 2011b). Prior research demonstrates that only benign envy, and not malicious envy, leads people to work harder on a subsequent irrelevant task (e.g., motivation to study). This may raise criticism regarding our work, as we reveal that envy, regardless of type, leads people to contact higher status others in the absence of competition and lower status others in the presence of competition. Most prior research on incidental envy is mostly interested in how envy, either benign or malicious, influences personal tasks. However, we believe that engaging in a personal task is qualitatively different from engaging in interpersonal behavior. Completing personal tasks appears to be related to improving the self, whereas interpersonal behavior (here, interpersonal contact) is more about enhancing positive self-evaluation. Enhancing self-evaluation does not necessarily mean that people become better. Hence, the varying influence of benign and malicious envy on personal tasks may not apply to interpersonal behavior. Thus, we believe that our paper does not contradict the previous findings on envy, but rather adds to the scant literature on the motivational properties of 
incidental envy. Nevertheless, it would be meaningful to further investigate the different effects of incidental malicious and benign envy on interpersonal behavior.

Second, given that this paper investigates interpersonal behavior, the strongest and best test would be to measure actual behavior. However, the characteristics of incidental emotions make it difficult to measure actual behavior in a real-life context, while not letting the participants know that they are under the influence of a certain emotion. Furthermore, the tendency to contact others may be hard to objectively measure based on actual behavior. Thus, further research needs to investigate how incidental envy influences actual interpersonal behavior in real-life contexts.

Finally, throughout three experiments we demonstrate that envy leads people to either contact higher or lower status others, depending on the absence or presence of competition. However, in our experiments we compare envy to a neutral emotion. It would be valuable to compare envy to other emotions that may influence subsequent interpersonal behavior. For example, admiration is known to be related to prosocial tendencies (Schindler et al. 2012) and is related to an improvement motivation like envy (Van de Ven et al. 2011b). Thus, it would be interesting to show how admiration affects subsequent interpersonal behavior.

〈Received March 29. 2018〉

〈Accepted July 20. 2018〉

\section{References}

Belk, Russell (2011), “Benign envy,” $A M S$ Review, 1(3-4), 117-34.

Bers, Susan A. and Judith Rodin (1984), "Socialcomparison jealousy: A developmental and motivational study," Journal of Personality and Social Psychology, 47(4), 766-79.

Buunk, Bram P., Rebecca L. Collins, Shelley E. Taylor, Nico W. Vanyperen, and Gayle A. Dakof (1990), "The affective consequences of social comparison: Either direction has its ups and downs," Journal of Personality and Social Psychology, 59(6), 1238-49.

Collins, Rebecca L. (1996), "For better or worse: The impact of upward social comparison on self-evaluations," Psychological Bulletin, 119(1), 51-69.

(2000), "Among the better ones," in Handbook of Social Comparison: Theory and research, ed. Jerry Suls and Ladd Wheeler, New York, NY: Kluwer Academic/Plenum Publishers, 159-71.

Deutsch, Morton (1949), “An experimental study of the effects of co-operation and competition upon group process," Human Relations, 2 (3), 199-231.

Durante, Kristina M., Vladas Griskevicius, Sarah E. Hill, Carin Perilloux, and Norman P. Li (2011), "Ovulation, female competition, and product choice: Hormonal influences on consumer behavior," Journal of Consumer 
Research, 37(6), 921-34.

Elster, Jon (1989), The cement of society: A survey of social order. Cambridge, UK: Cambridge University Press.

Festinger, Leon (1954), "A theory of social comparison processes," Human Relations, 7, 117-140.

Fischhoff, Baruch, Roxana M. Gonzalez, Deborah A. Small, and Jennifer S. Lerner (2003), "Judged terror risk and proximity to the world trade center," Journal of Risks and Uncertainty, 26, 137-51.

Goethals, George R. and John M. Darley (1977), "Social comparison theory: An attributional approach," in Social comparison processes: Theoretical and empirical perspectives, ed. Jerry Suls and Richard L. Miller, Washington, DC: Hemisphere Publishing, 259-78.

Hill, Sarah E. and David M. Buss (2008a), "The evolutionary psychology of envy," in Envy: Theory and Research, ed. Richard H. Smith, New York, NY: Oxford University Press, 60-70.

(2008b), "The mere presence of opposite-sex others on judgments of sexual and romantic desirability: Opposite effects for men and women," Personality and Social Psychology Bulletin, 34(5), 635-47.

Hill, Sarah E., Danielle Delpriore, and Phillip Vaughan (2011), "The cognitive consequences of envy: Attention, memory, and selfregulatory depletion," Journal of Personality and Social Psychology, 101(4), 653-66.
Hoogland, Charles E., Stephen Thielke, and Richard H. Smith (2016), "Envy as an evolving episode," in Envy at work and in organizations: Research, theory, and applications, ed. Richard H. Smith, Ugo Merlone, and Michelle K., New York, NY: Oxford University Press, 111-42.

Lange, Jens, Aaron C. Weidman, and Jan Crusius (2018), "The painful duality of envy: Evidence for an integrative theory and a meta-analysis on the relation of envy and schadenfreude," Journal of Personality and Social Psychology, Advance online publication. Lockwood, Penelope and Ziva Kunda (1997), "Superstars and me: Predicting the impact of role models on the self," Journal of Personality and Social Psychology, 73(1), 91-103.

Malatesta, Carol Z. and Carroll E. Izard (1984), "The facial expression of emotion: Young, middle-aged, and older adult expressions," in Emotion in adult development, ed. Carol Z. Malatesta and Carroll E. Izard, Beverly Hills, CA: Sage, 253-73.

Miceli, Maria and Cristiano Castelfranchi (2007), "The envious mind," Cognition \& Emotion, 21(3), 449-79.

Molleman, Eric, Jean Pruyn, and Ad Knippenberg (1986), "Social comparison processes among cancer patients," British Journal of Social Psychology, 25(1), 1-13.

Morse, Stan and Kenneth J. Gergen (1970), "Social comparison, self-consistency, and 
the concept of self," Journal of Personality and Social Psychology, 16(1), 148-56.

Mussweiler, Thomas, Katja Rüter, and Kai Epstude (2004), “The man who wasn't there: Subliminal social comparison standards influence self-evaluation," Journal of Experimental Social Psychology, 40(5), 689-96.

National Universities Ranking (accessed 2017, January 9), [available at http://colleges. usnews.rankingsandreviews.com/bestcolleges/rankings/national-universities].

Parrott, W. Gerrod (1991), "Experiences of envy and jealousy," In The psychology of jealousy and envy, ed. Peter Salovey, New York, NY: The Guilford Press, 3-30.

Parrott, W. Gerrod and Richard H. Smith (1993), "Distinguishing the experiences of envy and jealousy," Journal of Personality and Social Psychology, 64(6), 906-20.

Polman, Evan and Rachel L. Ruttan (2011), "Effects of anger, guilt, and envy on moral hypocrisy," Personality and Social Psychology Bulletin, 38(1), 129-39.

Preacher, Kristopher J. and Andrew F. Hayes (2004), "SPSS and SAS procedures for estimating indirect effects in simple mediation models," Behavior Research Methods, Instruments, \& Computers, 36(4), 717-31.

Salovey, Peter (1991), The psychology of jealousy and envy. New York, NY: Guilford Press.

Schindler, Ines, Juliane Paech, and Fabian Löwenbrück (2014), “Linking admiration and adoration to self-expansion: Different ways to enhance one's potential," Cognition and Emotion, 29(2), 292-310.

Silver, Maury and John Sabini (1978), "The perception of envy," Social Psychology, 41 (2), 105-11.

Smith, Richard H. (1991), "Envy and the sense of injustice" The psychology of jealousy and envy, ed. Peter Salovey, New York, NY: Guilford Press, 79-99.

Smith, Richard H., Sung Hee Kim and W. Gerrod Parrott (1988), "Envy and jealousy," Personality and Social Psychology Bulletin, 14(2), 401-9.

Suls, Jerry, Rene Martin, and Ladd Wheeler (2002), "Social comparison: Why, with whom, and with what effect?" Current Directions in Psychological Science, 11(5), 159-163.

Taylor, Shelley E., Bran P. Buunk, and Lisa G. Aspinwall (1990), "Social comparison, stress, and coping," Personality and Social Psychology Bulletin, 16(1), 74-89.

Taylor, Shelley E. and Marci Lobel (1989), "Social comparison activity under threat: Downward evaluation and upward contacts," Psychological Review, 96(4), 569-75.

Tesser, Abraham, Murray Millar, and Janet Moore (1988), "Some affective consequences of social comparison and reflection processes: The pain and pleasure of being close," Journal of Personality and Social Psychology, 54(1), 49-61. 
Van de Ven, Niels, Marcel Zeelenberg, and Rik Pieters (2009), "Leveling up and down: The experiences of benign and malicious envy," Emotion, 9 (3), 419-29. (2011a), "The envy premium in product evaluation," Journal of Consumer Research, 37(6), 984-98.

(2011b), "Why envy outperforms admiration," Personality and Social Psychology Bulletin, 37(6), 784-95.

Wheeler, Ladd and Kunitate Miyake (1992), "Social comparisons in everyday life," Journal of Personality and Social Psychology, 62 (5), 760-73.
Wills, Thomas A. (1981), "Downward comparison principles in social psychology," Psychological Bulletin, 90(2), 245-71.

Wood, Joanne V., Shelley E. Taylor, and Rosemary R. Lichtman (1985), "Social comparison in adjustment to breast cancer.," Journal of Personality and Social Psychology, 49(5), 1169-83.

(1989), "Theory and research concerning social comparisons of personal attributes," Psychological Bulletin, 106(2), 231-48. 


\section{$\langle$ Appendix〉}

Visual stimuli for the target-status manipulation (Experiment 2)

A. Higher status

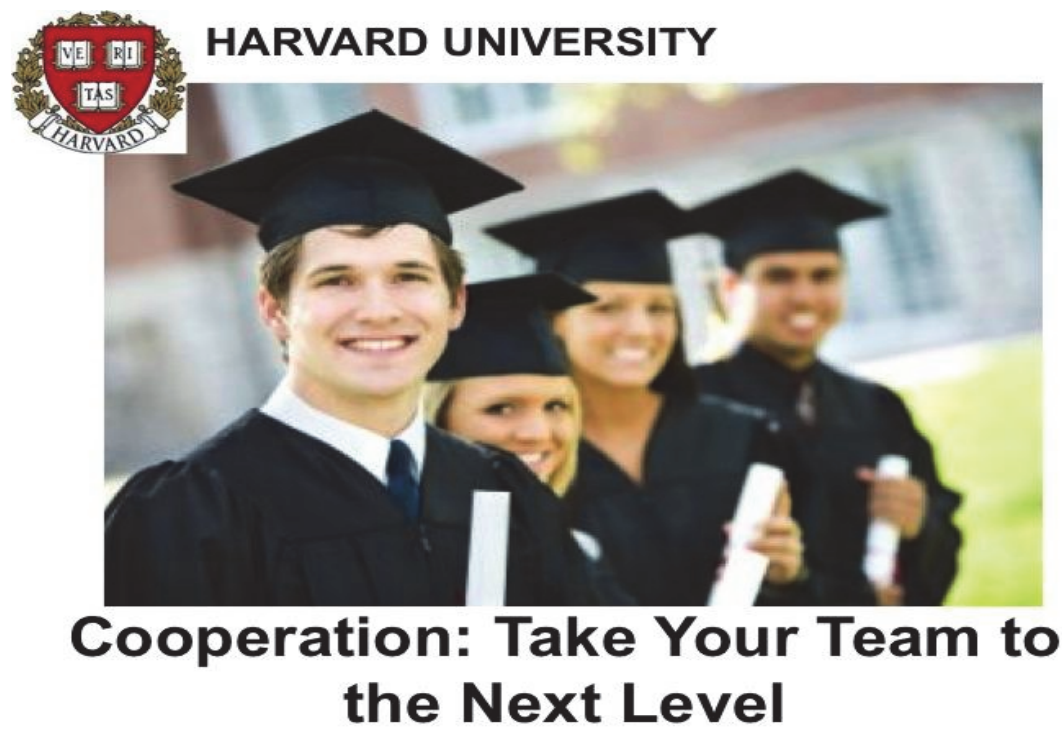

B. Lower status

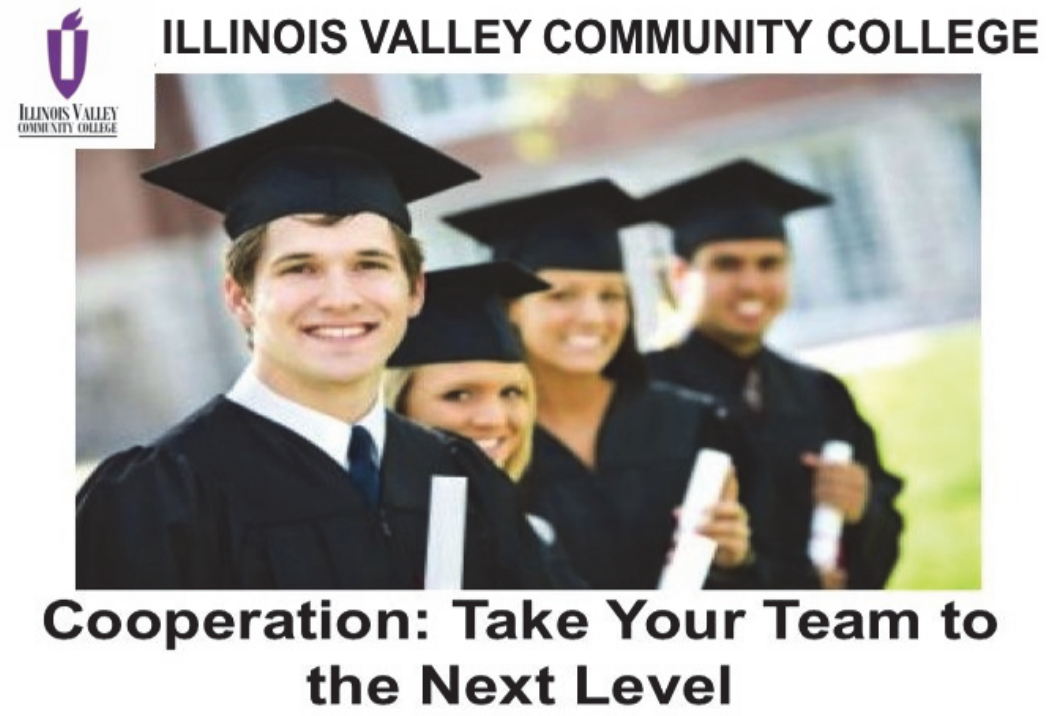

